\title{
Research on the Teaching Practice of Electronic Professional English in Mechanic Colleges
}

\author{
Yang Ling \\ Department of Electronic and Photoelectric Engineering, Xiamen Technical College \\ Xiamen 361102, China
}

\begin{abstract}
This paper illustrates the characteristics of professional English courses which have been paid more and more attention by mechanic college in recent years from four aspects. In view of the characteristics of professional English and combining with teaching practice, the author analyzes and discusses the current unsatisfactory teaching situation from the aspects of teaching materials, teaching contents, teaching strategies and evaluation methods, and puts forward some strategies to improve teaching quality.
\end{abstract}

\section{Keywords-Mechanic college; Electronic; English teaching}

\section{INTRODUCTION}

Mechanic College is a vocational education institution which aims at training highly skilled talents; it is the foundation of training professional technical talents in our country. It is a market-oriented education what aims at learning exquisite technology; hence, the courses must be in line with the current national conditions and industry demand. However, with the progress of the times, the rapid development of science and technology, the economic and trade has been globalized, the foreign-funded enterprises have got a continuous influx, the domestic enterprises have also rapidly entered the international market, and the technological equipment has been upgraded. Meanwhile, the enterprises get a higher and higher requirement for skilled personnel, in addition to professional knowledge, that should also be of English communication ability in certain industry. Especially in the electronics industry, most of the instruments and equipment, integrated circuits are imported, new electronic products are constantly emerging, industrial art and technology are constantly innovating, and the number of new words' abbreviation is increasing. All of these require professional talents in electronic major to use their English skills so as to communicate and learn from the relevant literature and the latest research results. In the course of the research on the course reform of electronic major, the author found that many enterprises clearly point out the importance of professional English [1].

At present, there are still many problems in electronic major's English teaching in mechanic colleges, the teaching quality can not meet the needs of the development of the situation, and the graduates in the higher mechanic colleges is far from the requirements of the society. In order to meet the needs of the development of the situation, it is inevitable to explore and reform the English teaching for this major, which is of great significance for the cultivation of compound electronic professionals.

\section{CharaCteristics OF ElECTRONIC ProfessionAl ENGLish}

Professional English [2], which means English for Special usage ("ESP"), electronic professional English, is an important specialized course for electrical majors, which is obviously different from general English [1]. It pays attention to the concept, principle, device, development and application of electronic field, almost all of them are narrative text, which contains certain professional common sense. In the aspect of teaching, English teaching focuses on broadening students' professional vocabulary, understanding the meaning of technical terms in certain industry, knowing the characteristics of professional English, and training and improving students' ability to integrate English with professional knowledge. Meanwhile, English teaching also try to improve the ability of students to independently read literature, device or product specifications, and to understand the professional content of the industry in order to acquire the latest scientific and technological knowledge, so as to lay a solid foundation for the students' future ability of the professional English knowledge processing and work-related business .In terms of content, electronic professional English presents the following characteristics, which also bring great difficulties to the students who have a weak foundation. The teaching effect is not good.

\section{A. Many complex long sentences}

Professional articles generally contain more profound and accurate principles and theorems, which makes scientific and technological articles use precise words, have many demonstrative pro-noun, and one sentence will contain several clauses, as well as strong professional knowledge. It is often difficult for students to translate such complex and long sentences in combination with their own professional knowledge. For example, the amplitude of a voltage waveform on an oscilloscope's screen can be determined by counting the number of centimeters $(\mathrm{cm})$, vertically, from one peak to the other peak of the waveform and the multiplying it by the setting of the volts/cm control. The range of voltage waveform in the oscilloscope's screen can be determined by the centimeter value of the longitudinal distance between the peak and the trough. To multiply this centimeter value to the set value of the $\mathrm{V} / \mathrm{cm}$ control button so as to get the amplitude of 
the voltage. This is a long sentence with a pair of compound sentences and a clause. And the 'it' here refers to the number of centimeters.

\section{B. Many non-finite verbs}

In general, there is only one verb in each simple sentence. When there are more than one clause and several verbs, only the main verb is chosen as the predicate, and the other verbs are expressed in the form of a non-finite verb. This often makes it difficult for students to distinguish the sequence of actions, to sort out the context of sentences, so as to understand and translate accurate sentences.

\section{Many passive voices}

In order to emphasize the objective things described in EST, it is often placed at the beginning of the sentence to highlight its importance, therefore, the passive voice will be overmuch. At this time, according to the Chinese custom, we can do not have to translate the sentence into passive voice.

\section{Many word formation}

The vocabulary in professional English has the characteristics of being professional, having more compound words and acronyms. Many words are polymorphic words, which are also nouns and can also be used as verbs, adjectives, adverbs or prepositions. In different disciplines or different majors there are often different word meanings, as well as a large number of professional terms and English acronyms, which can easily lead to misinterpretation and often bring trouble to students. At this point, we need to understand the meaning of the word by combining with professional knowledge and by the concept's background knowledge which involves in the content of the context. In the process of teaching, we can consciously introduce professional words and expand it.

\section{The Present Situation Of Teaching Practice At ELECTRONIC PROFESSIONAL ENGLISH [3]}

At present, the students in mechanic colleges and universities come from high school graduates, technical secondary school graduates and vocational school graduates. Their English is uneven, a small number of students have failed to achieve their learning goals in junior high schools, which have a seriously effect to their basic learning ability and enthusiasm, and even to the normal operation of the teaching plan. It has brought great obstacles to the teaching of professional English. The lack of students' vocabulary, the complex professional vocabulary, the complex sentences, and the lack of professional knowledge have led to the fact that many students can not understand the text even think the teachers speak in great detail and popularity in the traditional classroom. Therefore, and the teaching effect is not good. The results of teaching can not meet the requirements of the society for the students' professional English level. Hence, it is imperative to reform the teaching at electronic professional English.

\section{STRATEgIES To IMPRove The Quality OF TeAching [3] [4]}

According to the teaching practice in recent years, the author deeply analyzes the teaching contents, classifies and induces them, makes the teaching contents to be concrete, and draws lessons from the integrated teaching mode, uses the field teaching method, the enlightening teaching method, and so on. This paper summarizes the following aspects to improve the teaching quality of electronic professional English.

\section{A. Selection of appropriate teaching materials}

The choice of teaching material is an important step in teaching, it is the concrete embodiment of teaching outline and teaching content, and it plays an important role in teaching effect [4].With the rapid development of electronic information technology, the selected teaching materials must meet the following requirements: It is necessary to keep abreast of the frontier of modern electronic technology, to keep pace with the progress of professional technology, and to embody the characteristics of "new knowledge, new technology and practicability"; The content language expression must be accords with the student's "acceptability and comprehensibility"; The major knowledge points in English learning materials of the textbook contain the common technical terms and abbreviations, which can serve the students' professional English foundation; The textbook is equipped with audio material which have professionals with great pronunciation to read the text, it can also be used as a reference for the choice of teaching materials. Therefore, the choice of good teaching materials is the first step to achieve the teaching goals, and is the basis for developing students' English application ability. Teaching material is a part of the teaching content and a "carrier" to form the teaching content.

\section{B. Deepen the teaching content}

After several years of teaching experience, the author found that the conditions of running a school, the strength of teachers and the quality of students are different, it is very difficult to find common ESP teaching materials, and most of teaching materials can not fully meet the needs of teaching. Teachers can combine the students' professional English learning with the students' needs, expand the teaching contents, supplement the contents of the teaching materials what is lack, and expand the students' knowledge, according to the actual employment situation of the students. For example, adding the latest industry information, scientific research results, integrated chip manual, instrument and equipment specification, English design drawings, professional English literature, English job resume writing training, professional English software interface introduction, etc. With appropriate methods and techniques, students can adapt themselves to future study and work, pay attention to the cultivation of students' English ability in practical engineering applications, and make them master certain professional vocabulary and terminology and be of strong ability to read and translate general technical materials. 


\section{Diverse Teaching Methods}

In order to improve the teaching quality of the course, teachers should set up the teaching idea of "students as the main body, teachers as the secondary", avoid the teaching method of "full hall irrigation", and flexibly adopt the modern teaching methods such as heuristic, research and discussion methods to organize the teaching. Arouse students' enthusiasm for study [5]. Such as carefully preparing the class opening remarks or a clever question before class, or a group of pictures or videos connected with the course, etc., then start the text around the topic and enter the text explanation. The penetration of basic professional vocabulary, the interpretation of English instructions, the explanation of professional English vocabulary, the analysis of examples, the comparison of basic English, and the differentiation of the meaning of the same word in different situations; In class, we use standard audiobooks and multimedia demonstration courseware to assist the teaching. In the courseware, we try to use beautiful and real photos and pictures to display the text, repeat the structure analysis of the demonstration sentences, and turn them into simple ones and long sentences into short sentences. In the course of classroom teaching, we should try our best to interact and enliven classroom atmosphere, improve students' interest in learning, stimulate students' enthusiasm for learning, and help, encourage and guide students so as to build up students' self-confidence in learning professional English. Let them actively participate in learning, change their dependence on teachers to explain, and give full play to their potential. In addition, it should not only be limited to classroom teaching, but also be based on the study of the teaching materials used, according to different teaching content, flexible use of a variety of teaching methods to organize classroom teaching:

\section{1) Field Teaching Method}

In the classroom, properly move the classroom into the training room, teach in groups in the training room, use the physical knowledge of the instrument and equipment that the students have already skillfully used to explain, Such as entering the electronic instrument training room to learn the English interface of the GS-620 double track signal generator, let the students first operate the common buttons, then say the functions of each button, the teacher writes out the corresponding English, and analyzes the understanding skills; Such as the use of multimeter physical learning multimeter range selection switch on English and so on. So that students can easily master the oscilloscope, multimeter, AC-DC, resistance $\mathrm{R}$ full name, and by AC-DC homeopathic extension to the ADC, DAC explanation. It is believed that the classroom in which students can learn and practice in practice and discuss in groups can attract students' interest and greatly enhance the practicality of professional English.

\section{2) Computer Room Teaching-Task-based Teaching} Method

When teaching ESP courses, professional teachers should learn from the mode of "teaching, learning and doing" in professional courses, and carry out application-oriented taskdriven teaching in multimedia computer room. For example, English professional software such as EDA, protel99se, DXP, simulation software can be taught in the computer room, the task-driven mode can be used to teach, and the name of the menu bar of the specialized software can be learned. To guide students to study English in the professional knowledge and software operating methods. In order to enable students to quickly memorize all kinds of professional nouns in practice.

\section{3) Recall Teaching}

For the articles about the theory and principle of electronic major in the textbook [6], we can adopt "recall teaching", "recall teaching" means to recall the principles and laws that are to be expounded in the article. Then use this professional knowledge to help students understand the text. For example, using "recall teaching" to talk about resistance, capacitance, inductance, you can first take a few objects into the classroom. Students first recall the reading methods and characteristics of the three devices, and then look at the text to enhance students' confidence in the success of professional English learning. Promote the teaching process smoothly.

\section{4) Heuristic Teaching Method}

There are many synthetic words in English for science and technology, and they are also high frequency words in professional English. Understanding and mastering the origin and rules of these words will be of great help to the translation of these words and difficult sentences. For this kind of words, we can use the method of "heuristic teaching", which means that in the course of teaching, according to the content of teaching, starting from the students' reality, we can gradually guide the students to enlighten their thinking and arouse their enthusiasm. Promote students to study actively, connect knowledge with memory, guide students to simplify and absorb the difficult content.

Through these diversified teaching forms, active classroom atmosphere, let the students realize the necessity of learning professional English, truly master the knowledge of ESP course, so as to attach importance to the course of specialized English ideologically. Increase the enthusiasm of students to learn, and achieve better learning results. 


\section{Improving the Assessment Methods and Academic Evaluation Methods}

The examination of professional English should be different from that of English majors, and students' memory and understanding of professional knowledge [7], English vocabulary and grammar should not be assessed simply from the perspective of the final examination. Instead, we should focus on assessing the students' ability to use English comprehensively to solve related professional problems. This is the guarantee of cultivating students' English application ability. There are four parts for the calculation of students' total grades: Attendance scores $(10 \%)$, class participation performance scores $(10 \%)$, daily job tasks (10\%), mid-term exam scores $(30 \%)$, and final test scores $(40 \%)$, attach importance to training students' autonomous learning ability and emphasizing learning process assessment. For assignments to students, we can use the Internet or reference books to search for a piece of text, image, sound and video related to a certain knowledge point of the major, and send it to the teacher in English E-mail. And the use of reference books, electronic dictionaries to understand, in the classroom students to explain their own materials, teachers and other students to explain their comments and additions. Can also arrange English resume production tasks, rich variety of learning tasks can promote students to participate actively, give full play to their talents, improve their ability to apply. The final midterm exam covers most of the curriculum, focusing on the assessment of the ability to apply, so that students pay more attention to each examination link, improve the interest in learning, and promote the quality of teaching.

\section{CONCLUSION}

Learning professional English well will lay a good foundation for the study of electronic major students' professional knowledge and the future work in related professional fields. According to the practice of professional English teaching for many years, the author thinks deeply and studies, and draws the following conclusions: The teaching of electronic major English cannot be limited to teaching materials. According to the characteristics of professional English, such as long sentences, many technical terms, frequent and frequent use of acronyms, and so on, the teaching contents should be updated in accordance with the needs of students. To broaden students' vision, appropriately infiltrate and supplement the language knowledge of professional English to students, constantly optimize the teaching mode, combine various teaching methods, and allow students to participate in the whole classroom teaching activities as much as possible. And further realize the necessity of learning the course, so as to give full play to the enthusiasm of students to learn, and effectively promote the improvement of students' English ability.

\section{REFERENCES}

[1] Ding Chenyang. Discussion on Teaching Reform of Electronic Major English [J] .Science and technology innovation report 2014 no. 29.

[2] Zhu Yi-lun. English for Electronic Technology [M] .Electronic Industry Press, China (In Chinese)

[3] Peng Li. Study on English teaching for electronic majors [J] .New Campus, June 2014, No. 319.

[4] Wang Meng. Discussion on the construction of special purpose English teaching materials in higher vocational education $[\mathrm{J}]$.Study on the Theory of Urban Construction (Electronic version, 2014 / 12).

[5] Mo Xiaoling. The present situation and Teaching Reform of "Professional English" in Applied Electronic Information Engineering undergraduate Specialty [Journal papers] -Campus English (in the middle of the year.2014.12)

[6] Wang Ruizhen. A study on the present situation and Countermeasures of Electronic Major English Teaching in Secondary Vocational Schools [J] .overseas English, March 2014.

[7] Shen Shanshan. A probe into the Teaching of Electronic Major English for Electrical Specialty [J]. Journal of Jiamusi Institute of Education. 